\title{
Retrospective Study
}

\section{Preventable Deaths among HIV-Positive Patients: A Real-Life Perspective from a Teaching Hospital in Northern Mexico}

\author{
Andrea Ramirez Fontes, MD'; Juan Carlos Rodriguez Aldama, MD'; Luis Antonio Sanchez Lopez, MD²; \\ Samantha Flores-Treviño, PhD $^{3}$; César Adan Almendarez-Sánchez, MD ${ }^{4}$; Adrian Camacho Ortiz, PhD $^{1 *}$ \\ 'Department of Infectious Diseases, University Hospital Dr. Jose Eleuterio Gonzalez, Monterrey, Mexico \\ ${ }^{2}$ Council of State for Prevention and Control of HIVIAIDS, Nuevo León, Mexico \\ ${ }^{3}$ Department of Gastroenterology, University Hospital Dr. Jose Eleuterio Gonzalez, Monterrey, Mexico \\ ${ }^{4}$ Hospital Epidemiology Coordination, University Hospital Dr. Jose Eleuterio Gonzalez, Monterrey, Mexico
}

\section{"Corresponding author}

Adrián Camacho-Ortiz, MD PhD

Department of Infectious Diseases, University Hospital Dr. Jose Eleuterio Gonzalez, Monterrey, Mexico; Tel. +52 (8I) 834827 67;

E-mail:a acamacho_md@yahoo.com

\section{Article information}

Received: October $8^{\text {th }}, 2018$; Revised: November II th 2018 ; Accepted: December $4^{\text {th }}$, 2018; Published: December $8^{\text {th }}, 2018$

\section{Cite this article}

Fontes AR, Aldama JCR, Lopez LAS, Flores-Treviño S, Almendarez-Sánchez CA, Ortiz AC. Preventable deaths among HIV-positive patients: A real-life perspective from a teaching hospital in Northern Mexico. HIVIAIDS Res Treat Open J. 2018; 5(I): 9-14. doi: 10.17I40/HARTOJ-5-I28

\section{ABSTRACT}

\section{Introduction}

Antiretroviral therapy (ART) in patients infected with human immunodeficiency virus (HIV) are more effective and better tolerated and for this reason the gap between life expectancy of an HIV-seropositive individual and a seronegative one has been closing. This study was carried out to identify the main causes of death in in HIV-infected patients in a tertiary-care hospital as well as relevant sociodemographic and clinical factors that contribute to their prognosis.

Aim

The aim of the present study is to identify the main causes of death in HIV/AIDS patients as well as relevant sociodemographic and clinical factors that contribute to their prognosis.

Methods

A retrospective cohort was conducted with confirmed HIV-infected adult patients who died between January 2010 and January 2017. Sociodemographic and clinical data were taken from their clinical records to carry out a statistical analysis on the mortality of these patients and the relevant factors that contributed.

Results

A total of 120 patients with in-hospital mortality and HIV diagnosis were included, of these, 55\% were allocated to an AIDS defining event, $75.8 \%$ had an HIV diagnosis of less than 6 months from their death, $88.3 \%$ received HIV testing for suspicion or confirmation of an AIDS defining event, and 50\% had two or more active AIDS defining events at admission.

Conclusion

A major public health concern is a late HIV/AIDS diagnosis, a situation that is occurring in Mexico. Despite universal access to antiretroviral treatment, the most common causes of mortality in HIV-positive patients are still AIDS defining events, mainly tuberculosis and other opportunistic infections that with a prompt diagnosis might have been prevented if these patients had initiated early antiretroviral therapy.

\section{Keywords}

HIV/AIDS therapy; Tuberculosis; Mortality; México.
} 


\section{INTRODUCTION}

Since the introduction of universal access to antiretroviral theSrapy (ART) in Mexico on 2001, treatment regimens for patients infected with human immunodeficiency virus (HIV) have been more effective, simpler and better tolerated. It is for this reason that the gap between life expectancy of an HIV-seropositive individual compared to a seronegative one has been closing from up to 13 years in 2013 to +24 years in 1996-1997, according to international data. ${ }^{1}$ Other factors influencing survival between HIV-positive patients are the mode of transmission, the ethnic group, and the absolute CD4 T-lymphocyte count at the start of ART, all of which are important considerations when treating these patients. There may be broader benefits to the increasingly liberal HIV treatment guidelines, including reductions in death caused by non-AIDS-related diseases (such as cardiovascular and chronic liver disease). ${ }^{2}$

According to the "Advances on Millennium Development Goals" report published by the United Nations in 2015, the mortality rate per 100,000 inhabitants for HIV/AIDS in Nuevo Leon, Mexico has been constantly over the national goal of 3.5. Mexican data published by the National HIV/AIDS Prevention and Control Center on November 27, 2017 revealed that since 1983 until said year, Nuevo Leon has had around 3\% of the total national number of AIDS cases. There has been an irregular incidence rate in the total HIV-positive patients between 2012 and 2017 probably attributable to the improvement of detection techniques of primary infection (phases 1 and 2 of the natural history of the disease). ${ }^{3}$ Nonetheless, statistically, these numbers are proportional to the intensification of AIDS cases as well. According to the National Epidemiologic Vigilance System, $72.6 \%$ of HIV-positive cases have been diagnosed with one or more AIDS defining events (ADE); therefore, in spite of the progress made by Mexico in diagnosing HIV, the main causes of death of people living with HIV are still AIDS-related complications due to late treatment with low baseline CD4 counts. $^{4-6}$

Regardless of CD4 counts, ART for 180 days is associated with $79 \%$ decrease in all-cause-in-hospital mortality. ${ }^{7}$ Among patients with CD4 counts $>500$, the deferral of ART to lower CD4 counts is associated with an increased risk of death of $94 \%$ compared with early initiation therapy. ${ }^{8}$ Early diagnosis of HIV infection as well as the medical attention that comes with it and access to ART in combination with adherence and retention are crucial for reducing complications, achieving viral suppression and preventing viral resistance and/or transmission. ${ }^{9,10}$ Intensive treatment with a regimen that inhibits different steps in the HIV life cycle has been suggested as a strategy for improving antiretroviral combination therapy. ${ }^{11}$ Evidence suggests that mental illness and substance abuse are major risk factors for poor adherence and virologic failure, encouraging physicians to screen and concomitantly treat with serotonin reuptake inhibitors ${ }^{12-14}$ added to the current recommendation for sexually transmitted disease ${ }^{15}$ and tuberculosis (TB) screening. ${ }^{16,17}$

The main opportunistic diseases in high-income countries are esophageal candidiasis, Pneumocystis jirovecii pneumonia (PCP), and Kaposi Sarcoma (KS) according to two major cohort studies. ${ }^{18,19}$ Mexican and Latin American cohort studies for HIV mortality have consistently showed Mycobacterium tuberculosis infection counting as one of the first three main causes of death in HIV-infected patients. ${ }^{7,20-21}$ The socioeconomic factor is importantly associated with the high burden of HIV/TB mortality, despite free ART being made available in low-income countries. ${ }^{22}$ ART is known to be around $70 \%$ protective against TB incidence. Isoniazid preventive therapy against TB is now recommended for 36 months and further reduces the risk of active TB by $30-50 \%{ }^{23}$ TB prevalence is particularly high in individuals with CD4 counts below 200 cells $^{24}$ and the rate of progression to active TB disease is 5 to $8 \%$ per year between HIV-infected patients with latent TB, compared to a $10 \%$ lifetime risk in the general population. ${ }^{25}$ In Mexico, TB needs to be accounted for as a major public health concern in HIV-infected patients.

\section{METHODS}

This was an observational retrospective cohort that included all hospitalized patients with confirmed HIV infection and all cause in-hospital mortality from January 2010 to January 2017. The study was carried out in the "Dr. José Eleuterio González" University Hospital of the Universidad Autonoma de Nuevo León (a 500bed teaching hospital located in the northern city of Monterrey, Mexico).

Data were recovered from hospital clinical records including sociodemographic factors such as age, education level, mode of virus acquisition, motive for HIV testing, time and adherence to ART, history of ART and causes of discontinuation in such cases. Hospital length of stay, intensive care unit (ICU) stay, comorbidities, AIDS-defining events active at admission, concomitant infections, and timing from diagnosis to death were recorded. AIDS-defining events were categorized based on the expanded list of CDC classification (1993) of AIDS related diseases. ${ }^{26}$

The direct cause of mortality and secondary events that lead to death were also documented. In those cases with concomitant TB, multidrug resistance was investigated. Ambulatory patients and hospitalized patients who were discharged with improving health were excluded. Missing clinical records were not included. A preventable death was defined as a person living with HIV who was diagnosed during the previous 6 months from their death or without active therapy; regarding active AIDS-defining events.

The present study was submitted and approved by the ethics committee with registration number IF18-00002. For statistical analysis SPSS version 21.0 was used. Mean, median, percentages and rates were calculated, and graphics were made with Graphpad Prism 7.

\section{RESULTS}

During the study period, a total of 517 HIV-positive patients were admitted to the hospital; of those, 120 had in-hospital deaths and thus were included. From the total sample 92 patients $(76.7 \%)$ were men, mean age was 40 years (range 18-78), the main presumable 
mode of transmission was sexual and 67 patients (55\%) referred themselves as men who have sex with men (MSM) (Figure 1). The most frequent comorbidities were diabetes mellitus in 18 patients $(15 \%)$, liver disease and peripheral vascular disease in 12 patients each $(10 \%)$. Less than a third $(27.9 \%)$ finished their basic studies of middle school, $33.3 \%$ went on to finish high school, and $26.7 \%$ had finished college or had a professional degree.

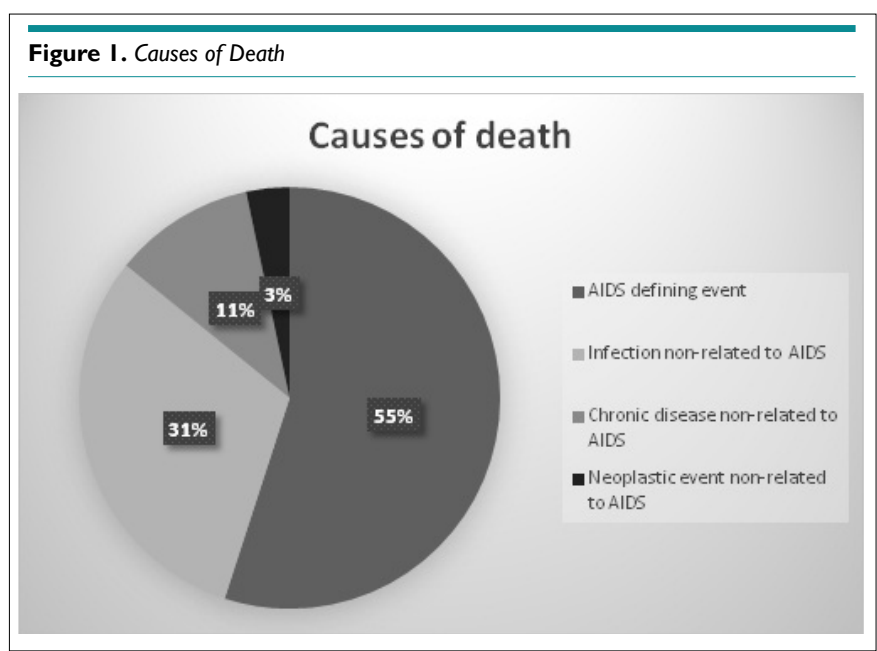

Twenty-six patients were found to have concomitant infections (21.7\%). Of these Venereal Disease Research Laboratory test (VDRL) was positive in 9 patients $(7.5 \%), 8$ patients had surface antigen for hepatitis B virus (6.7\%), 6 had antibodies against hepatitis $\mathrm{C}$ virus (5\%), 2 patients had papilloma virus $(1.7 \%)$ and 1 patient had herpes simplex virus $(0.8 \%)$ (Table 1$)$.

Over a half of the study group passed away due to AIDSdefining events (66 patients, 55\%), 37 (31\%) from an infection not related to AIDS, 13 to chronic disease not related to HIV (11\%), and $4(3 \%)$ patients died of a neoplastic event not related to AIDS (Figure 2). The length of stay of each patient varied from 1 to 65 days with a median of 12 days; also 43 patients (35\%) required an Intensive Care Unit (ICU) stay for a mean of 11.2 days (range 1 to 41).

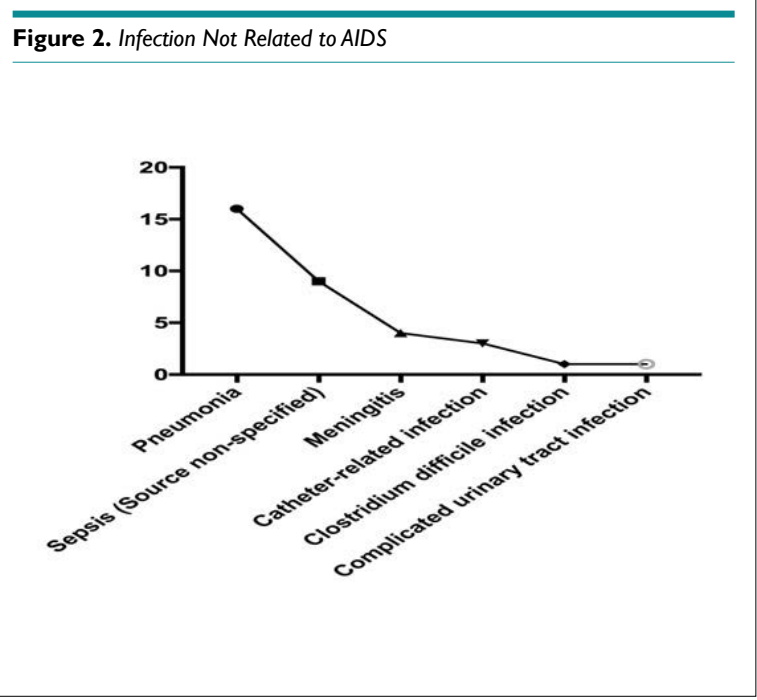

\begin{tabular}{|c|c|}
\hline Characteristic & Cases, n (\%) \\
\hline Male & 92 (76.7\%) \\
\hline Age, years & 40.4 (range 18-78) \\
\hline \multicolumn{2}{|l|}{ Education } \\
\hline 0 years & $14(11.5)$ \\
\hline $1-6$ years & $34(27.9)$ \\
\hline 7-9 years & $40(33.3)$ \\
\hline$>9$ years & $32(26.7)$ \\
\hline \multicolumn{2}{|l|}{ Comorbidities } \\
\hline Diabetes mellitus & $18(15 \%)$ \\
\hline Hepatic & $12(10 \%)$ \\
\hline Peripheral vascular & $12(10 \%)$ \\
\hline Renal & $6(5 \%)$ \\
\hline Cardiovascular & $4(3.3 \%)$ \\
\hline Dyslipidemia & $2(1.7 \%)$ \\
\hline Collagen & I ( $(0.8 \%)$ \\
\hline \multicolumn{2}{|l|}{ Concomitant infections } \\
\hline VDRL & $9(7.5 \%)$ \\
\hline HBV & $8(6.7 \%)$ \\
\hline $\mathrm{HCV}$ & $6(5 \%)$ \\
\hline HPV & $2(1.7 \%)$ \\
\hline HSV & $\mathrm{I}(0.8 \%)$ \\
\hline \multicolumn{2}{|l|}{ Timing from diagnosis to death } \\
\hline$<6$ months & $91(75.8 \%)$ \\
\hline 6-24 months & $12(10 \%)$ \\
\hline 24 months -5 years & $9(7.5 \%)$ \\
\hline$>5$ years & $8(6.7 \%)$ \\
\hline Had HIV diagnosis prior to hospitalization & $63(52 \%)$ \\
\hline \multicolumn{2}{|l|}{ Cause for HIV testing } \\
\hline Confirmed AIDS defining event & $94(78.3 \%)$ \\
\hline Suspicion of AIDS defining event & $12(10 \%)$ \\
\hline Non-specified & $9(7.5 \%)$ \\
\hline HIV+ partner & $2(1.7 \%)$ \\
\hline Risk perception & $3(2.5 \%)$ \\
\hline Routine testing & 0 \\
\hline \multicolumn{2}{|l|}{ AIDS events active } \\
\hline $0-1$ & $60(50 \%)$ \\
\hline $2-3$ & $56(46.7 \%)$ \\
\hline$>4$ & $4(3.3 \%)$ \\
\hline \multicolumn{2}{|l|}{ ART $(n=26)$} \\
\hline $0-6$ months & $9(7.5 \%)$ \\
\hline$>6$ months- $<12$ months & $4(3.3 \%)$ \\
\hline$>12$ months $-<24$ months & $3(2.5 \%)$ \\
\hline$>24$ months $-<60$ months & $4(3.3 \%)$ \\
\hline$>60$ months ( 5 years) & $6(5 \%)$ \\
\hline ART active & $18(15 \%)$ \\
\hline
\end{tabular}

Regarding time of diagnosis, 91 (76\%) had their diagnosis within 6 months prior to their death; of these, fifty-nine $(48.4 \%)$ were diagnosed during the hospitalization in which they died, and 
sixty-three patients $(51.6 \%)$ were already diagnosed at the time of their passing. One hundred and six patients $(88.3 \%$ ) had the HIV test performed for clinical suspicion or confirmation of an AIDSdefining event. Sixty patients (50\%) had two or more active AIDSdefining events upon admission. Of the previously diagnosed patients 26/63 (41\%) had started ART, although just 18/63 (28\%) were actively taking it and 13/63 (20\%) within a time frame of less than one year from their death. AIDS-defining events were investigated overall, even if they were not associated with the main cause of death (Figure 3 shows the frequency).

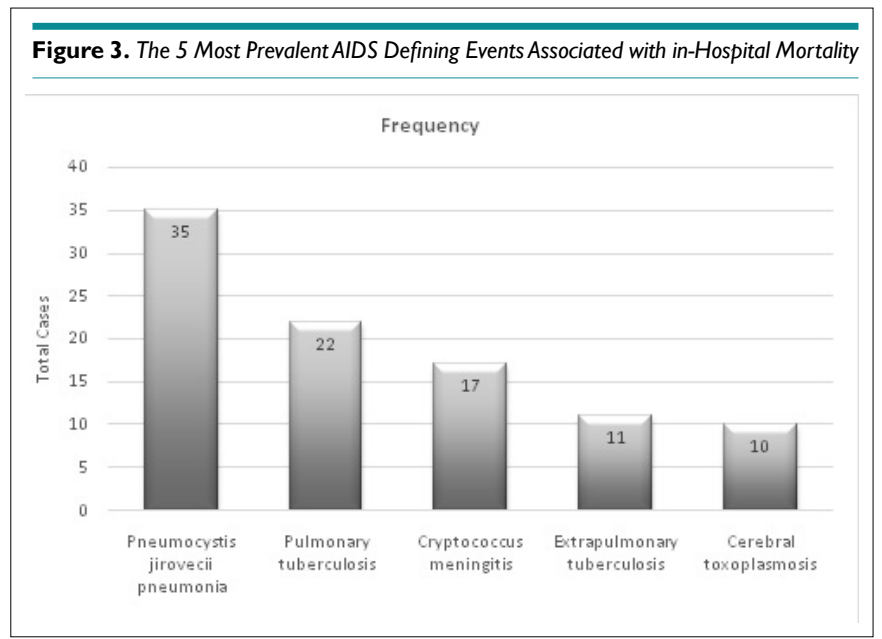

Thirty-three cases of TB were confirmed of the total 140 AIDS defining events (24\%) (Table 2). Eighteen had a positive PCR test (Cepheid XpertTB MTB/RIF) and one was rifampin resistant, the other 15 patients were diagnosed either with biopsy or culture. The two most frequent causes of death were of a respiratory nature (respiratory failure and acute respiratory distress syndrome) predominantly caused by infections (PCP, TB, hospitalacquired pneumonia in $49 \%$ of the total sample).

\begin{tabular}{|c|c|}
\hline AIDS-Defining Event & Cases, $\mathrm{n}$ \\
\hline Pneumocystis jirovecii pneumonia & 35 \\
\hline Mycobacterium tuberculosis (pulmonary) & 22 \\
\hline Cryptococcosis (extrapulmonary) & 17 \\
\hline Mycobacterium tuberculosis (extrapulmonary) & 11 \\
\hline Toxoplasmosis (brain) & 10 \\
\hline Candidiasis (esophageal, trachea, bronchia or lung) & 9 \\
\hline Cytomegalovirus retinitis (with loss of vision) & 6 \\
\hline Recurrent pneumonia ( $>2$ episodes in I-year period) & 5 \\
\hline Coccidioidomycosis (disseminated or extrapulmonary) & 4 \\
\hline Cryptosporidiosis (>I month) & 4 \\
\hline Cytomegalovirus disease (other than liver, spleen or nodes) & 4 \\
\hline Kaposi's sarcoma & 4 \\
\hline Encephalopathy (HIV-related) & 3 \\
\hline Lymphoma (primary of brain) & 2 \\
\hline Lymphoma (Burkitt or immunoblastic) & 1 \\
\hline Progressive multifocal leukoencephalopathy & 1 \\
\hline Cervical cancer (invasive) & 1 \\
\hline $\begin{array}{l}\text { Herpes simplex: chronic ulcers }>1 \text { month and bronchitis, } \\
\text { pneumonitis or esophagitis }\end{array}$ & I \\
\hline
\end{tabular}

\section{DISCUSSION}

The present study analyzes causes and context of deceased patients diagnosed with HIV infection in a single hospital in Northern Mexico. The Dr. Jose Eleuterio Gonzalez University Hospital is as a tertiary-care referral unit in Monterrey. Despite the achieved progress made by Mexico in HIV diagnosis and universal access to treatment, there is great need for earlier diagnosis.

In 2006, a study was published where mortality from high-income countries (North America and Europe) was compared with low-income countries (Africa, Asia, and South America). The result was lower T-cell levels, higher mortality (peak during the first few months from initiating treatment) and variations in the antiretroviral drugs administered in low-income countries. ${ }^{27}$ The peak mortality on our sample was indeed within the first few months of diagnosis (77\% of patients). Mexico has high hospitalization rates because of AIDS-related events and a significant proportion of patients are without or with a recent ( $<6$ months) diagnosis of HIV. ${ }^{6,21,28}$ It is important to emphasize that there were no tests done for routine screening on the analyzed sample, despite the existent access to routine testing.

Late detection management is a multidisciplinary effort, patients must have a strong support system and serious non-AIDS events should be prevented as there are studies that demonstrate higher rates of mortality than those AIDS-related. ${ }^{29}$ Comorbid conditions must be actively sought, such as cardiovascular, renal, hepatic disease, and malignancies. Furthermore, immune reconstitution inflammatory syndrome must be watched for, as it associates to the extent of CD4 immune suppression and degree of viral suppression following the initiation of ART. Treatment guidelines recommend initiating antiretroviral therapy within two weeks for most opportunistic infections. ${ }^{30}$

Taking into consideration that $91 / 120$ patients had their HIV diagnosis made during the previous 6 months from their death in addition to only 29 of those patients dying of a non-AIDS related condition, and 3 patients being actively treated with ART, on the basis of the findings by Baez-Saldaña et al. ${ }^{7}$ We theorize that with prompt diagnosis, earlier and aggressive treatment plus adequate retention and engagement in care, a total of 49 to 62 deaths might have been prevented in this cohort.

In the present study only 3 deaths were attributed to a neoplastic condition not related to HIV and 4 deaths to a cardiovascular (CV) disease. In 2015, Cerrato et al published a study where the ratio between deaths from $\mathrm{CV}$ disease and deaths from AIDS-related disease increased in HIV positive patients from highincome nations. ${ }^{31}$ In addition, international data show a statistically significant risk for congestive heart failure, infarction and ischemic disease of $50 \% .^{30-32}$ Nevertheless, the sample prevalence and mortality from CV disease was low in contrast with these studies, information that displays a different pattern of mortality rates from $\mathrm{HIV}$ in Mexico. A larger sample with additional geographic states involved needs to be studied and analyzed to confirm this finding.

The present study has limitations. Because of its retro- 
spective nature, the data gathering process was challenging. Not all patients were subjected to CD4 counts and viral load for HIV because these tests are performed by the health ministry and are not routinely sent during hospitalization, although with the information from patients that were in fact tested (Table 3) we feel we have a clear picture of the advanced stages of HIV infection in which we engage our newly diagnosed patients.

\begin{tabular}{|c|c|}
\hline Table3. Immunological Status & jects \\
\hline CD4 counts $n=28$ & Viral load $n=20$ \\
\hline Mean I6I.5 (3-1,699) & Median $252,960(0-I, 800,000)$ \\
\hline
\end{tabular}

Co-infected patients with TB pose a great challenge and, in our findings, almost 1 of every 4 patients that died had TB $(24 \%)$. These results are higher than the $17.9 \%$ reported by Martin-Onreat ${ }^{21}$ and the $20.5 \%$ reported by Baez-Saldaña. Surprisingly, there was only one patient who reported resistance to rifampin, given that higher rates of resistance have been registered in the region according to Flores-Treviño who reported the highest rate in Nuevo León (33.3\%), just below Chiapas (66\%) and Mexico City (53\%). ${ }^{33}$ Because patients were newly diagnosed with both infections during their final hospitalization, they were not previously exposed to anti-tuberculous drugs. Prophylaxis for Pneumocystis Pneumonia (PCP) and treatment for latent TB in HIV-positive patients has proven to be the cornerstone for opportunistic infection-free periods. Regretfully, in the present study, preventable opportunistic infections were highly lethal, raising the need for earlier diagnosis of HIV infection and prompt treatment and/or prophylaxis for opportunistic infections. Poor adherence was also prevalent; $22 \%$ of previously treated patients were either not actively taking their medications and previous treatments or reasons for discontinuing management were not clear. Retention of patients in health systems and treatment adherence are essential to change mortality rates in Mexicans living with HIV.

\section{CONCLUSION}

Despite having universal access to ART, the current study shows strong evidence that the main causes of death in HIV-infected patients in Mexico are AIDS-defining events, the majority of which are preventable. A priority for the Mexican public health system should be to enhance HIV routine testing.

\section{CONFLICTS OF INTEREST}

The authors declare that they have no competing interests.

\section{REFERENCES}

1. Samji H, Cescon A, Hogg RS, et al. Closing the gap: Increases in life expectancy among treated HIV-positive individuals in the United States and Canada. PLoS One. 2013; 8(12): e81355. doi: 10.1371/journal.pone.0081355

2. Cheung CC, Ding E, Sereda P, et al. Reductions in all-cause and cause-specific mortality among HIV-infected individuals receiving antiretroviral therapy in British Columbia, Canada: 2001-2012. HIV Med. 2016; 17(9): 694-701. doi: 10.1111/hiv.12379

3. Palella FJ, Delaney KM, Moorman AC, et al. Declining morbidity and mortality among patients with advanced human immunodeficiency virus infection. HIV outpatient study investigators. N EnglJ Med.1998; 338(13): 853-860. doi: 10.1056/nejm199803263381301

4. Hernandez-Romieu AC, Del Rio C, Hernandez-Avila JE, et al. CD4 Counts at entry to HIV care in Mexico for patients under the "universal antiretroviral treatment program for the uninsured population," 2007-2014. PLoS One. 2016; 11(3): e0152444. doi: 10.1371/journal.pone.015244

5. Pineirua A, Sierra-Madero J, Cahn P, et al. The HIV care continuum in Latin America: Challenges and opportunities. Lancet Infect Dis. 2015; 15(7): 833-839. doi: 10.1016/s1473-3099(15)00108-5

6. Silverman-Retana O, Bautista-Arredondo S, Servan-Mori E, Lozano R. AIDS-related early mortality in Mexico between 2008 and 2012. Salud Publica Mex. 2015; 57 Suppl 2: s119-126.

7. Baez-Saldana R, Villafuerte-Garcia A, Cruz-Hervert P, et al. Association between highly active antiretroviral therapy and type of infectious respiratory disease and all-cause in-hospital mortality in patients with HIV/AIDS: A case series. PLoS One. 2015; 10(9): e0138115. doi: 10.1371/journal.pone.0138115

8. Kitahata MM, Gange SJ, Abraham AG, et al. Effect of early versus deferred antiretroviral therapy for HIV on survival. $N$ Engl J Med. 2009; 360(18): 1815-1826. doi: 10.1056/NEJMoa0807252

9. Mugavero MJ, Davila JA, Nevin CR, Giordano TP. From access to engagement: measuring retention in outpatient HIV clinical care. AIDS Patient Care STDS. 2010; 24(10): 607-613. doi: 10.1089/ apc. 2010.0086

10. Sabin CA, Howarth A, Jose S, Hill T, et al. Association between engagement in-care and mortality in HIV-positive persons. AIDS. 2017; 31(5): 653-660. doi: 10.1097/qad.0000000000001373

11. Collier AC, Coombs RW, Schoenfeld DA, et al. Treatment of human immunodeficiency virus infection with saquinavir, zidovudine, and zalcitabine. AIDS clinical trials group. $N$ Engl J Med. 1996; 334(16): 1011-1017. doi: 10.1056/nejm199604183341602

12. Horberg MA, Silverberg MJ, Hurley LB, et al. Effects of depression and selective serotonin reuptake inhibitor use on adherence to highly active antiretroviral therapy and on clinical outcomes in HIV-infected patients. J Acquir Immune Defic Syndr. 2008; 47(3): 384-390. doi: 10.1097/QAI.0b013e318160d53e

13. Tegger MK, Crane HM, Tapia KA, Uldall KK, Holte SE, Kitahata MM. The effect of mental illness, substance use, and treat- 
ment for depression on the initiation of highly active antiretroviral therapy among HIV-infected individuals. AIDS Patient Care STDS. 2008; 22(3): 233-243. doi: 10.1089/apc.2007.0092

14. Lesko CR, Todd JV, Cole SR, et al. Mortality under plausible interventions on antiretroviral treatment and depression in HIVinfected women: An application of the parametric g-formula. Ann Epidemiol. 2017; 27(12): 783-789.e782. doi: 10.1016/j.annepidem.2017.08.021

15. Hoots BE, Torrone EA, Bernstein KT, Paz-Bailey G. Self-reported chlamydia and gonorrhea testing and diagnosis among men who have sex with Men-20 US cities, 2011 and 2014. Sex Transm Dis. 2018; 45(7): 469-475. doi: 10.1097/olq.0000000000000786

16. Selwyn PA, Sckell BM, Alcabes P, Friedland GH, Klein RS, Schoenbaum EE. High risk of active tuberculosis in HIV-infected drug users with cutaneous anergy. JAMA. 1992; 268(4): 504-509. doi: $10.1001 /$ jama.268.4.504

17. Cain KP, McCarthy KD, Heilig CM, et al. An algorithm for tuberculosis screening and diagnosis in people with HIV. N Engl J Med. 2010; 362(8): 707-716. doi: 10.1056/NEJMoa0907488

18. Djawe K, Buchacz K, Hsu L, et al. Mortality risk after AIDSdefining opportunistic illness among HIV-infected persons--san francisco, 1981-2012. J Infect Dis. 2015; 212(9): 1366-1375. doi: $10.1093 /$ infdis/jiv235

19. Mocroft A, Sterne JA, Egger M,et al. Variable impact on mortality of AIDS-defining events diagnosed during combination antiretroviral therapy: Not all AIDS-defining conditions are created equal. Clin Infect Dis. 2009; 48(8): 1138-1151. doi: 10.1086/597468

20. Crabtree-Ramirez B, Caro-Vega Y, Shepherd BE, et al. Time to HAART initiation after diagnosis and treatment of opportunistic infections in patients with AIDS in Latin America. PLoS One. 2016; 11(6): e0153921. doi: 10.1371/journal.pone.0153921

21. Martin-Onraet A, Pineirua-Menendez A, Perales-Martinez D, et al. In-hospital mortality in HIV-infected patients: 10 years after the implementation of universal access to HAART in Mexico. Salud Publica Mex. 2015; 57 Suppl 2: s163-170.

22. Kabudula CW, Houle B, Collinson MA, et al. Socioeconomic differences in mortality in the antiretroviral therapy era in agincourt, rural South Africa, 2001-13: A population surveillance analysis. Lancet Glob Health. 2017; 5(9): e924-e935. doi: 10.1016/ s2214-109x(17)30297-8
23. Ellis PK, Martin WJ, Dodd PJ. CD4 count and tuberculosis risk in HIV-positive adults not on ART: A systematic review and metaanalysis. PeerJ. 2017; 5: e4165. doi: 10.7717/peerj.4165

24. Day JH, Charalambous S, Fielding KL, Hayes RJ, Churchyard GJ, Grant AD. Screening for tuberculosis prior to isoniazid preventive therapy among HIV-infected gold miners in South Africa. Int J Tuberc Lung Dis. 2006; 10(5): 523-529.

25. Selwyn PA, Hartel D, Lewis VA, et al. A prospective study of the risk of tuberculosis among intravenous drug users with human immunodeficiency virus infection. N Engl J Med. 1989; 320(9): 545550. doi: 10.1056/nejm198903023200901

26. 1993 Revised classification system for HIV infection and expanded surveillance case definition for AIDS among adolescents and adults. $M M W \mathrm{R}$ Recomm Rep. 1992; 41(RR-17): 1-19.

27. Braitstein P, Brinkhof MW, Dabis F, et al. Mortality of HIV1-infected patients in the first year of antiretroviral therapy: Comparison between low-income and high-income countries. Lancet. 2006; 367(9513): 817-824. doi: 10.1016/s0140-6736(06)68337-2

28. Bravo-Garcia E, Ortiz-Perez H. Analysis of HIV/AIDS mortality in Mexico from 1990 to 2013: An assessment of the feasibility of millennium development goals by 2015. Gac Med Mex. 2016; 152(6): 819-830.

29. Freiberg MS, Chang CC, Kuller LH, et al. HIV infection and the risk of acute myocardial infarction. JAMA Intern Med. 2013; 173(8): 614-622. doi: 10.1001/jamainternmed.2013.3728

30. Cerrato E, Calcagno A, D'Ascenzo F, et al. Cardiovascular disease in HIV patients: From bench to bedside and backwards. Open Heart. 2015; 2(1): e000174. doi: 10.1136/openhrt-2014-000174

31. Marcus JL, Leyden WA, Chao CR, et al. HIV infection and incidence of ischemic stroke. AIDS. 2014; 28(13): 1911-1919. doi: $10.1097 /$ qad.0000000000000352

32. Butt AA, Chang CC, Kuller L, et al. Risk of heart failure with human immunodeficiency virus in the absence of prior diagnosis of coronary heart disease. Arch Intern Med. 2011; 171(8): 737-743. doi: 10.1001/archinternmed.2011.151

33. Flores-Trevino S, Mendoza-Olazaran S, Garza-Gonzalez E. Drug resistance and molecular epidemiology of Mycobacterium tuberculosis in Mexico: A systematic review. Salud Publica Mex. 2014; 56(1): 63-77. doi: 10.21149/spm.v56i1.7324 